\title{
CORRELATION AMONG CAR DEPENDENCY, SOCIAL STATUS AND CAR USE IN JAKARTA
}

\author{
Ayu Kharizsa \\ Data and Information Technology Center, General Secretariat of Ministry of Transportation, Jakarta Pusat, INDONESIA \\ kharizsa@gmail.com
}

Sigit Priyanto

Civil ad Environmental Engineering Department, Universitas Gadjah Mada, Yogyakarta, INDONESIA

spriyanto2007@ugm.ac.id

Ann Jopson

University of Leeds, London, UK

A.F.Jopson@its.leeds.ac.uk

\begin{abstract}
Aims of this research are to determine the prominent factor behind car dependency, examine the correlation between the factors that indicate car dependency, and the correlation between social status and car use in Jakarta. The primary question of this research is "What are the influence factors behind car dependency in Jakarta? Does prestige influence car use behavior in Jakarta?" By using Jakarta as a case study, the research applies Factor Analysis and Logistic Regression Analysis based on Theory of Planned Behavior. It used to measure individual's behavior based on attitudes toward behavior, subjective norm, and perceive behavior. The result shows that factors of dependency in term of car users consist of the starting place, habits, and control belief. While factors on car dependency for car users on occasion are intention and control belief. Correlation between prestige and car use is identified based on attitudes and subjective norm. For car users, attitudes are influenced by higher degrees of prestige which is slightly contrary to people who use cars occasionally. Other indicators of prestige are car types which can influence people's behavior in using the car. The conclusion which can be drawn from the results are no significant correlation found between car dependency and social status, but significant in the case of correlation between car use and social status.
\end{abstract}

Keywords: theory of planned behavior, habit, intention, control belief, prestige.

\section{INTRODUCTION}

The aim of this research is to examine the main reason behind using cars and finding a correlation among car dependency, social status and car use in Jakarta. In order to measure car dependency, this research uses the "Theory of Planned Behavior" (TPB) method to identify reasons for the behavioral approach. Such rich primary data have been collected through an online questionnaire using 'Bristol Online Survey' (BOS) software. The data collection uses 'snowballing' method with purposive sampling addressed to people who commute to Jakarta for work or educational purpose. The sampling includes people who travel from residential areas or from starting point in Jakarta to workplace or education place. The area might be the main city, and other satellite areas such as Bogor, Depok, Tangerang, and Bekasi (BODETABEK), under normal conditions. The result from this research will be taken into consideration for transport policy in Jakarta. Elements that are included in this study relate to instrumental and affective factors in the transport sector.

Just like any other metropolitan city, Jakarta has its own issues in term of the transportation sector. It is not considered easy to provide adequate infrastructure and public transport in a developing country such as Indonesia, or other developed countries. It also encounters other local problems due to human resource, high population, and urbanization. However, the biggest problem is high congestion during peak hours. The interesting part in this Jakarta case is that the citizens understand that using cars will increase the congestion, they know that it can contaminate the environment, and $63 \%$ of the people interviewed also answered that they feel frustrated due to the congestion. However, they still use their private vehicle for their mobility. Theory of Planned Behavior (TPB) is a method that provides means for identifying prominent factors based on three main variables. These variables are used to find factors that lead to the formation of the behavior of private car users. TPB defines three variables, i.e. behavioral belief (attitudes), normative 
norm (subjective norm), and control belief (perceived behavioral control) (Ajzen, 1991). Through this method, it can be easier to sort prominent factors that influence people's choices for using cars and it helps policy makers in Jakarta to decide what kind of policy they should provide.

Litman \& Laube (2002) mentioned that car dependency happens when automobile travel directly relates to automobile-oriented land use pattern then decreases another alternative. Automobile or car dependency is followed by losses in the transport and economic sectors such as higher vehicle expenses, decrease in travel choices, increase in road and parking facility cost, congestion, accidents, and many environmental impacts. Besides the economic sector, there are other affected sectors, for instance, according to (Newman \& Kenworthy (2006), there are side effects of car dependency in urban qualities such as loss of pedestrian area, viable public transport, jobs access and other conveniences which align with urban life.

\section{CAR DEPENDENCY, SOCIAL STATUS AND CAR USE}

Jakarta, the main city of Indonesia is one of the most highly populated cities in the world (Suryo, et al., 2007) with a population of 9.6 million in 2010 which increases $1.46 \%$ each year, the population density of Jakarta is $14,694.55 / \mathrm{km}^{2}$. This statistic further increases during the peak hours on weekdays when people from satellite areas also travel into the city for work or educational purposes. Presentation of the trips from inner and outside Jakarta are $72.95 \%$ and $27.05 \%$ respectively. As well as another urban area in developing country, the biggest problem in Jakarta is congestion.

Travel behavior is complex, and choices are affected by a wide range of factors, including journey distance, availability and location of infrastructure and services, and individual circumstances, characteristic, habits and attitude (Anable, et al., 2006). Litman \& Laube (2002) revealed that car dependency does not stand alone, it also influences another sector including transportation and land use factors. Decreasing number of people using alternative modes may occur by inconvenience in facilities. Stage (2009) mentioned that car dependency can be found when people live far away from their workplace and they prefer to drive. Then, Mackett (2002)notices that the implication of car dependency is not only the car use but also a perception that if they do not use the car, the activity could not be done. Car dependency occurs because of dynamic situation that happens eventually aligned with their personal situation (Goodwin, 1997). Figure 1 shows the Cycle of Automobile Dependency (CAD), the starting point of this cycle could be in every point of that cycle.

\subsection{Social Status and Car Dependency Understanding}

According to Litman \& Laube (2002), the car gives a benefit to users but not in all sectors, due to the higher expense and environmental cost. It was found by Cullinane and Cullinane (2003) in Hong-Kong. 38\% of people stated that it is necessary to own a car for lifestyle, $46 \%$ declared that it is quite necessary and other $15 \%$ stated not necessary. That means car in Hong Kong is such a lifestyle, not the function. Banister (2011) revealed that cities in developing countries are more tendencies to buy a car as soon as they can afford it, even in the low-density city they approach a car as a lifestyle.

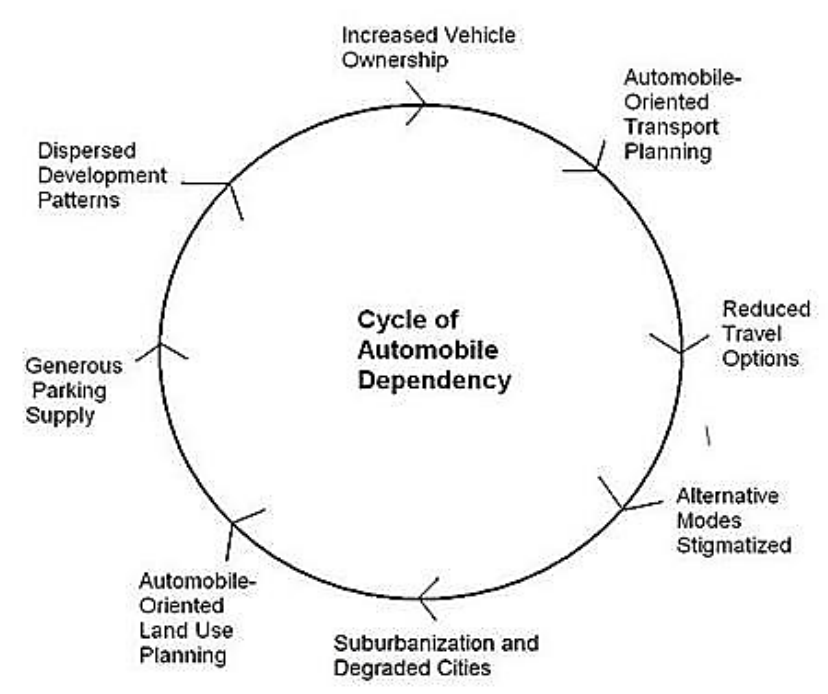

Figure 1. Cycle of Automobile Dependency (CAD)

\subsection{Theory of Planned Behavior (TPB)}

TPB is a theoretical account about how a number of variables being combined to determine behavior. Ajzen (1991) developed this theory to explain human behavior and predict further behavior from human preceding behavior. Theory of planned behavior has divided into three main variables which are; (a) Behavioral belief about personal evaluation in term of own perception being unlikely or likely. (b) Normative belief about influenced of social pressure to perform the behavior. (c) Control belief about self-efficacy to perform the behavior.

Anable (2005) applied TPB as a theoretical behavioral approach to measuring how attitude influences behavior and used this method to treat people in 
different ways. Clustered factors analysis was used to split the type of car user into 6 categories and found that perceived behavioral control as important variables to determine people's intention and behavior. As resulted in Gardner (2009), the habit has a stronger effect toward people's behavior rather than intention. Intention results are inversely proportional with habit in term of behavior involvement. Then, Bamberg and Schmidt (2003) found that TPB is better than norm activation modeled by Schwartz (1977) in term of people's behavior.

\section{METHOD}

This report shows factors behind car dependency in Jakarta and behavioral approach with the theory of planned behavior (TPB). The results are presented in narrative and descriptive explanations (see Figure 2).

\subsection{Study Area Selection}

The people who have been asked to fill the questionnaire are those who travel to Jakarta for work and educational purposes. There are several basic conditions applicable to the respondents of the questionnaire, namely:

a) The journey timeline: The trip they describe should be their first trip from their respective hometowns to Jakarta, on the first day of the week when they travel for work or education purpose.

b) The weather condition: During the journey, the weather should be fine, which means, there should be no heavy rains and people should be able to walk through the roads under normal weather conditions.

c) The urgency factor: The sample respondents should not be in a hurry to reach their place of work or education.

\subsection{Questionnaire development}

The questionnaire has been developed using inputs from previous research reports that mention about car dependency, social status and theory of planned behavior and spreads by Bristol Online survey (BOS) as tools recommended by the University of Leeds. The key questions on car dependency have been adapted from (Anable, 2005). The questions on TPB have been adapted from Paris \& Broucke (2008) to define variables about attitudes and subjective norms. This research refers to Verplanken \& Orbell (2003) to find out the strength of habit (Gardner, 2009) and to indicate intentions behind car use. Other questions regarding perceived behavioral control are referred to Ajzen
(1991). Concerning to social status, the questions have been developed using a reference from (Lois \& LópezSáez (2009).

\subsection{Sampling}

According to Atkinson \& Flint (2001), Snowballing Sampling is defined as an advanced technique to reach the research subjects or targeted population by expanding the researcher's potential contact. With sample size 385 to validate the questionnaire based on Raosoft (tools to calculate sample) and Slovin's formula.

\subsection{Questionnaire and measure}

This questionnaire follows a non-parametric model with ordinal, nominal and scale question types. The ordinal questions mostly use the Likert scale with four level measurements. The non-parametric model can make intuitive feeling measurement simpler and easier to summarize (Hollander, et al., 2013). The final questionnaire consists of 30 questions divided into four pages and seven sections. Primary data were got from an online questionnaire which 385 data in a month to analyze, while secondary data was gained from the Statistic center of Jakarta called Statistic Bureau (BPS, 2014), POLDA Metro, SITRAMP and the other data was extracted from some official websites of the government.

\subsection{Statistical analysis}

The data is compiled using factor analysis to define prominent factors among TPB Variables. Factor analysis is a statistical technique that is used to simplify the data complexity and to reduce duplicate data from a set of correlated variables.

This research uses confirmatory factor analysis, the variables are based on TPB analysis that defines attitude, subjective norm and perceived behavior control. It is identified through data collection which consists of 314 households that own car, 159 respondents use cars as their main mode of conveyance and 155 respondents use cars on occasion. Hence there are clearly two different kinds of car users, a group of people who use cars actively for traveling to work and place of study and the group of people who use cars for some occasion. Both these groups are measured using factor analysis to find distinct behavior behind their two choices. 


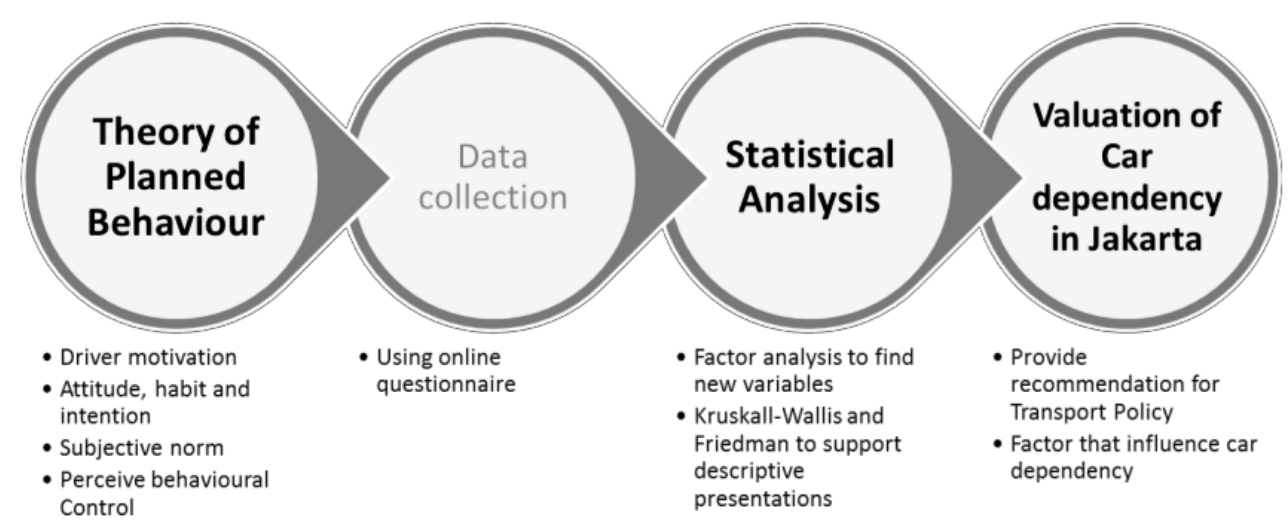

Figure 2. Research Flow Chart

\section{RESULTS AND DISCUSSIONS}

\subsection{Socio-Demographic}

Describes into six basic answers which are municipalities (based on respondent's residential place in greater Jakarta from where the journey begins), gender, age group, education level, occupation and income level.

The age group data type is non-symmetric in nature due to most of the people being in the age range of 2635 years. Skirbekk (2004) stated that people between ages 25-34 are in a stable productivity stage of their lives. They are numerate, have a good verbal aptitude, clerical ability, finger dexterity and general intelligence.

Education level influences people's time management which affects mode choice. Thus further analysis can identify whether education levels influence car dependency or not. Kawaguchi \& Wakamatsu (2012) classified income levels into three groups, i.e. low-income group (less than 1.5 million rupiahs $(<£ 80)$ ), medium income (between 1.5-6.0 million rupiahs (£80-£316)) and high-income group (above 6.0 million $(>£ 31)$ ).

The starting place mentioned in this section is the point where the respondents start to travel to their place of work or education. As shown in Table 1, 38\% journey in Jakarta is influenced by outer city region of Jakarta and the other $62 \%$ come from inner Jakarta. In inner Jakarta, about $42 \%$ people use the car as their main mode, it contains $29 \%$ people using the car as a driver and $13 \%$ using the car as a passenger for their daily activity.

\subsection{Car Dependency Results}

a) Regular car user

The derived variables consist of TPB bullets points. The new variables are "Habit", "Awareness", "Emotive", "Intention", "Instrumental", "Time Travel", "Control Belief", and "Prestige". With KMO 0.732 and sig. $<0.0005$ in factor analysis. According to logistic linear analysis, the sig. T-test from new variable crossed with car dependency question shows that starting place $\left(X_{1}\right), \operatorname{Habit}\left(X_{2}\right)$ and Control belief $\left(X_{3}\right)$ has significance dependence.

$\operatorname{Logit}(P)=-0.520+0.213 X_{1}+0.712 X_{2}-0.557 X_{3}$

b) On occasion car user

The derived variables consist of TPB bullets points. The new variables are "Habit", "Intention", "Time Travel", "Awareness", "Travel Cost", "Control Belief", "Emotive", "Prestige", and "Emotion". With KMO 0.669 and sig. $<0.0005$ in factor analysis. In logistic linear, the significant test shows that intention $\left(X_{1}\right)$ and control belief $\left(X_{2}\right)$ as primary factors that influence car user on occasion.

$\operatorname{Logit}(P)=-1.104+0.855 X_{1}-0.870 X_{2}$

\subsection{Measurement of social status, attitude and} subjective norm

Variable affecting prestige is based on their attitude and subjective norm to show prestige in car user behavior. Although there is no significant correlation between car dependency and prestige, this measurement looking for prestige factor behind car user. Thus, next section examines the correlation between social status questions with both behavior indicators. 
Table 1. Respondents' starting place

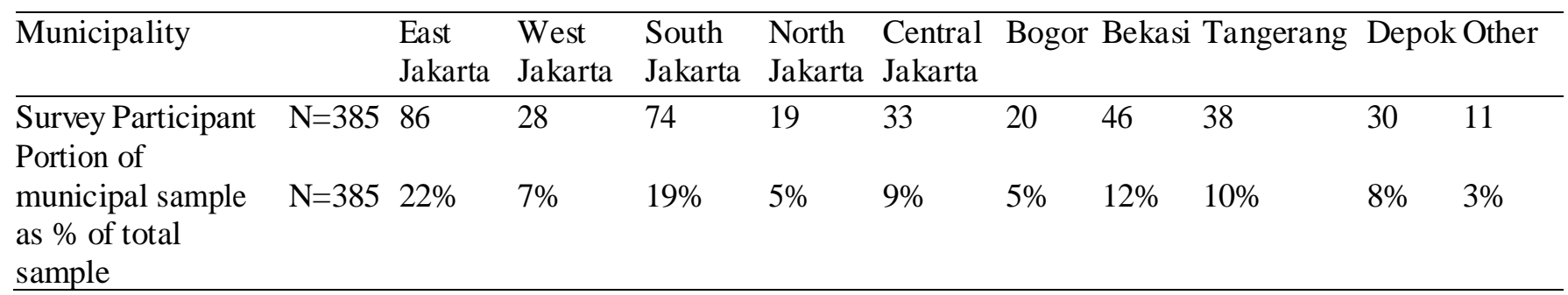

The method to analyze the data is same with the previous section, using factor analysis and logistic regression.

a) In the case of regular car user, the factor analysis separates into three components has made in social status variables named "prestige indicator", "city car preference" and "family car preference". Logistic regression analysis shows that attitude has a higher value compared with the subjective norm. It can be concluded that car user group, the attitude has many influences to prestige when using a car.

b) In the case of on occasion car user, the factor analysis separates into two groups which are "prestige indicator" and "city and family car preference". The value for subjective norm regression is higher than attitudes. It means people in this group use cars with more influences from other people around them.

\subsection{Social status and car preferences}

Correlation between car preference and social status for car user showing that car with type A (Classy and elegant) and B (Family car, expensive and show prestige) are shows correlation among all social status variable which are "distinguish me from other", "Better car better life", "Give me prestige" and "show my taste" with correlation value for type A are 0.209 , $0.438,0.389$, and 0.347 , respectively and for type B are $0.299,0.431,0.378$, and 0.269 , respectively. D car type, (City car and cheap but still show existence) shows social status as "give me prestige" with correlation value 0.201. For car type C (Family car have lot capacity and cheap) and E (city car, cheap and support mobility) do not show any correlation with car status. This correlation also exists in car user on occasion with the same car type. People are encouraged to buy a luxury car to show a prestige and wealth life even they got it with funding.

\section{CONCLUSIONS}

This study shows that people who use cars for traveling to their place of work or education are affected by three variables, i.e. the starting place from where they commence the journey, their habits and their control belief. While people who use cars for any occasion other than for traveling to work or place of education, their intention, and control belief are the main reason of car dependency. However, control belief variables have a negative value on car dependency indicators, which means if people can manage their self- efficacy they can reduce car use in the future. Habit is the main factor of car dependency in car users (Gardner, 2009). Cullinane \& Cullinane (2003) mentioned about intentions being an important factor that controls car users' behavior and results in a reduction of car usage. Otherwise, self-efficacy in control belief is also a strong factor to encourage people to reduce car usage (Anable, 2005).

The relevance of status social and car use in Jakarta is measured from attitudes and subjective norms. Logistic regression analysis revealed that attitude has a bigger influence on social status for car users. Subjective norm has more influence on the car users who use them on occasion. The other factor is that of prestige measure which can be indicated in the preference of car with A type (Classy, elegant and expensive) and B-type (Family car, expensive and shows prestige); this becomes an indicator to measure social status and car usage. Cars do not directly show social status but people who were interviewed, as a part of their study, stated that owning an expensive car implied higher social status than an old or inexpensive car.

In Jakarta, car dependency can be caused by captive area in their neighborhood. So, people do not have transportation option. It can be more attractive to do some research in public transportation around the area. And also do a research in public infrastructure and facility so can be concluded the main reason behind dependency from instrumental reason. Another option for future research it will be interesting if the researcher does a research based on income level. it will appear another factor such as flexibility or safety reason as car user in high income or other intangible reason that followed by car use in Jakarta. 


\section{REFERENCES}

Ajzen, I., 1991. The theory of planned behavior.. In: Organizational Behavior and Human Decision Processes. Elsevier Inc, pp. 179-211.

Anable, J., 2005. Complacent Car Addicts or Aspiring Environmentalists? Identifying Travel Behavior Segments Using Attitude Theory. Transport Policy, pp. 65-78.

Anable, J., Lane, B. \& Kelay, T., 2006. An Evidence Base Review of Public Attitudes to Climate Change and Transport Behavio, London: Department for Transport.

Atkinson, R. \& Flint, J., 2001. Accessing Hidden and Hard-To-Reach Populations: Snowball Research Strategies. Social Research Update, Volume 33, pp. 14.

Bamberg, S. \& Schmidt,, P., 2003. Incentives, Morality, or Habit? Predicting Students Car Use for University Routes with the Models of Ajzen, Schwartz, and Triandis. Environment and Behavior, Volume 35, pp. 264-285.

Banister, D., 2011. Cities, Mobility, and Climate Change. Journal of Transport Geography,, pp. 15381546.

BPS, 2014. Statistical Year Book, Jakarta: Statistic Bureau of Republic Indonesia.

Cullinane, S. \& Cullinane, K., 2003. Transportation Research Part D: Transport and Environment. In: Car Dependence In A Public Transport-Dominated City: Evidence From Hong Kong, pp. 129-138.

Gardner, B., 2009. Transportation Research Part F: Traffic Psychology and Behavior. In: Modelling Motivation and Habit in Stable Travel Mode Contexts., pp. 68-76.

Goodwin, P., 1997. Mobility and Car Dependence in Traffic and Transport Psychology, Theory, and Applications. New York: Pergamen Press.

Hollander, M., Wolfe, D. \& Chicken, E. (2013), E., 2013. Nonparametric Statistical Methods. John Wiley $\&$ Sons.
Kawaguchi, H. \& Wakamatsu, M., 2012. Travel Behaviors of the Disabled in Jakarta Metropolitan Area.

Litman, T. \& Laube, F., 2002. Automobile Dependency and Economic Development, Canada: Victoria Transport Policy Institute.

Lois, D. \& López-Sáez, M., 2009. The Correlation between Instrumental, Symbolic and Affective Factors as Predictors Of Car Use: A Structural Equation Modeling Approach. In: Transportation Research Part A: Policy and Practice, pp. 790-799.

Mackett, R., 2002. Increasing Car Dependency Of Children: Should We Be Worried?, pp. 29-38.

Newman, P. \& Kenworthy, J., 2006. Urban Design to Reduce Automobile Dependence. Opolis.

Paris, H. \& Broucke, S. V. D., 2008. Transportation Research Part F: Traffic Psychology and Behavior,. In: Measuring Cognitive Determinants of Speeding: An Application of the Theory of Planned Behavior, pp. 168-180.

Schwartz, S., 1977. Normative Influences on Altruism in L. Berkowitz. In: Advances in Experimental Social Psychology. San Diego:: Academic Press, pp. 221-279.

Skirbekk, V., 2004. Age and Individual Productivity: A Literature Survey. Vienna Yearbook of Population Research, pp. 133-153.

Stage, L., 2009. Transportation Research Part A: Policy and Practice. In: Car Use: Lust and Must. Instrumental, Symbolic and Affective Motives for Car Use, pp. 147162.

Suryo, R., Fan, C. \& Weiler, S., 2007. Commuting choices and congestion taxes in industrializing Indonesia. The Social Science Journal, pp. 253-273.

Verplanken, B. \& Orbell, S., 2003. Reflections on Past Behavior: A Self-Report Index of Habit Strength. Journal of Applied Social Psychology, Volume 33, pp. 1313-1330. 